Send your letters to the Editor,

British Dental Journal,

64 Wimpole Street

London

W1G 8YS

Email bdj@bda.org

Priority will be given to letters less than 500 words long.

Authors must sign the letter, which

may be edited for reasons of space.

\section{GROWING DISBELIEF}

Sir, we read the opinion piece on The industrialisation of the dental profession (BDJ 2009; 206: 347-350) with a growing sense of disbelief. Everyone is entitled to their opinion but we would hope that the opinions published in the $B D J$ would bear a little closer relationship to reality than this one.

Cottingham and Toy see developments in the way the profession operates as an example of a classic production line approach being applied to the provision of dental services. They cite the increased use of ancillary staff members and the breaking down of treatment plans into manageable segments handled by different professionals as a justification for that opinion.

This strikes us as a bizarre interpretation of the facts as we know them.

We have state funded services in England and Wales which operate under a contract that renders the use of ancillary staff less cost effective. That appears to be reducing dilution of the profession rather than the opposite. At the same time we have a burgeoning non-state funded sector which is dealing directly with the patient for its funding but selling a high quality relationship-based service provided by a named operative; precisely the opposite of the opinion of Cottingham and Toy. When large dental service providers have established independently funded services with treatment provided by whichever clinician happens to be handy at the time, they have not prospered.

Practices that use ancillary staff regularly do not parcel out treatment plans and patients do not routinely have their procedures carried out by three or four different people. There is a clear acceptance by many patients that prevention of periodontal disease begins with regular visits to the hygienist - the one and only group of ancillaries to have proved their independent value in terms of surgery space and earning capacity. Dental nurses have demonstrated their value to the profession as support workers making surgery work infinitely more productive but it is not easy to see how a dental nurse can do very much if there is no dentist present. Taking radiographs and applying fluoride varnish will assist progress with treatment but it hardly constitutes an industrial process.

A hygienist and a dentist working together in a practice could never be described as a 'factory' and the level of industrialisation is nil.

There are times in every dentist's life when it is necessary to resort to the support, advice and specialist treatment offered by a consultant or a better qualified colleague, but this cannot be regarded as routine practice. Most GDPs are capable of delivering a well-rounded and competent treatment plan for most patients, with occasional help from their professional friends.

There is a separate argument that would support the establishment of bigger centres for dentists to operate from that would allow the development of all forms of clinical excellence under one roof. This would assist the patient in not having to find several independent sources to build their own care pathway. Our existing primary care businesses are commonly housed in unsuitable buildings and there will come a time when a move is necessary. That does not equate to adopting a factory approach to the provision of care, just better premises offering economies of scale.
Patients have begun to place a greater value on their healthy mouths and dentists have recognised that the key factor in a successful patient relationship is a very personal level of interaction.

The principle of industrialisation is diametrically opposed to that most precious of healthcare principles - the constant effort to place the patient's welfare ahead of the welfare of the clinical team and ahead of the financial aspirations of the business owner.

We have seen examples where the provision of healthcare by 'clinical teams' leads to fragmented care leaving the patient battered from pillar to post tracing the next step on their clinical journey. Patients often complain of falling through the gaps in service provision and a lack of directly attributable responsibility that belongs with one named individual.

This rejection of industrial methods is not based on some retrospective vision of 'the good old days', it is based on the experience of thousands of colleagues who realise that their patients are their best asset, richly deserving to be looked after in the way that patients prefer - by the person they have come to trust. The 'factory' is not a welcome innovation and it is certainly not an inevitable one; it is an unwelcome interloper and should be rejected in the best interests of our patients, ourselves and our profession.

One of the major reasons the corporate bodies in UK primary dental care have failed to make as much progress as they would like is that their business model is disliked by many patients who want to know before they enter the surgery who exactly is waiting to see them.

There may be some who think a factory approach to dentistry is the right 
way forward but it seems to us to be out of touch with the views of patients who, in our opinion, should be listened to more carefully.

J. Renshaw, E. Crouch, I. Gordon, P. Batchelor

Drs Toy and Cottingham respond: We welcome the opportunity to respond to Messrs Renshaw, Crouch, Gordon and Batchelor. We believe they have made a significant mis-interpretation of our personal views. They seem to have focused on just one section of the paper (What will it take to remain effective?) and therefore we feel that they have taken our remarks out of context.

Firstly, it is important to establish that much of the 'opinion' reported here comes out of a research project, which included an extensive literature review, partially cited here. Secondly, we report the opinion of members of a variety of professions, including those involved in healthcare. We also found wet-fingered dental professionals (currently involved in the practice in the $U K$ ) responding and relating to the concept. We are simply reporting on and interpreting our findings.

The content and tone of their letter implies that we positively promote industrialisation and that the patients' needs must necessarily be ignored in favour of the desire for increased 'productivity'. This is precisely the opposite of our view. The research shows that industrialisation is a social change that has been influencing the relationship between the professions and society for many years. We believe and clearly state the patient must be seen 'as a human being with the complexities of human needs and wants'. It is our strong desire to see that patients receive a high quality of dental care, whether they are state or privately funded, and this was a major reason for writing the article. We also wanted to make the profession aware of the social forces acting upon it.

As we state, the industrialisation of dental services may be seen in the state-control of commissioning (PCT contracts), the right of non-dentists to perform certain dental services (eg GDC Scope for Practice Guidelines), and UDA targets (although not emphasised in our article). We respectfully suggest that this is not a 'bizarre interpretation of the facts'. It is also a fact that the Dental Body Corporates continue to grow in size and number, and that practices and their teams are getting larger. Meanwhile, more dental schools are training more DCPs. The social paradigm of industrialisation is already affecting primary dental care.

If the social and political forces continue to bear down on dentistry (as the research shows they have on other professions) then, as educationalists, we believe it is imperative that we help the modern dentist learn how to cope with the changing relationship between society and the dental profession - for the benefit of patients. As we say in the paper, 'Industrialisation requires the dental profession to speak clearly for the upholding of standards of care in the changing world as no other body has the specialised professional knowledge to represent this'. We hope that Messrs Renshaw, Crouch, Gordon and Batchelor would agree with us on this point, at least.

DOI: 10.1038/sj.bdj.2009.561

\section{ELDER ABUSE}

Sir, Dr A. Korada expresses justifiable dismay over the 'terrible condition' of oral health among people living in care homes, and the almost complete lack of daily oral health care $(B D J 2009 ; 206$ : 396). This problem is not confined to Newcastle, but extends throughout the developed world. Medline-listed papers have been published since the mid-1970s from researchers distributed through North and South America, the Middle and Far East, Europe and Australia, all describing similar neglect of frail older residents.

Due partly to dental workforce shortages and service commissioning anomalies, the majority of UK care home residents, particularly when home-bound, are unable to access dental services. Therefore, any oral health care falls upon the nursing staff, despite the fact that dental topics are scarcely touched upon during medical and nursing education. Nearly all personal care for residents is in any event carried out by lower-paid care assistants who usually have no formal training, and among whom oral health is the most hated and least performed care procedure.
Despite the publication of BSDH guidelines for oral care of long-stay residents, ${ }^{1}$ and a number of initiatives to educate and motivate care home staff to carry out daily oral hygiene care for residents who desire help, ${ }^{2-4}$ no lasting successful solution has been found due to the diverse factors contributing to the situation. A multiplicity of healthcare-related agencies is involved with care of frail elders, from the Department of Health, health authorities and primary care trusts down to individual care homes and individual dental teams. Recent publications by the $\mathrm{BDA}^{5}$ and the Department of Health ${ }^{6}$ have identified the shared responsibility of all these agencies for the current state of affairs, and have recommended actions that must be taken at all levels in order to achieve a remedy.

Neglect of residents' oral condition leads to impairment in quality of life, chewing ability and nutrition, and may place elders at risk of unwanted sequelae from chronic diseases, such as diabetes, cardiovascular disease and chest infections, where associations with poor oral health are known. With increasing numbers of older people now retaining natural teeth, the challenge of enabling frail dependent individuals to enjoy a healthy mouth is progressively more difficult. Publicly funded services often do not provide adequate coverage for routine dental care or domiciliary visits. Scarce finances are often spent transporting residents to emergency care when regular preventive care would be a more efficient use of funds.

Clearly, there must be a multidisciplinary response - and urgently - to the increasing oral health concerns of older adults who present with functional dependency, chronic disease, and are homebound or living in residential care. Anything less would be a form of elder abuse.

\section{H. Frenkel} Bristol

1. Fiske J, Griffiths J E, Jamieson R, Manger D.

Guidelines for oral care for long stay patients and residents. British Society of Disability and Oral Health, 1996. http://www.bsdh.org.uk/guidelines/ longstay.pdf

2. Simons D, Baker $P$, Jones B, Kidd E A M, Beighton D. An evaluation of an oral health training programme for carers of the elderly in residential homes. Br Dent J 2000; 188: 206-210.

3. Frenkel H F, Harvey I, Newcombe R. Improving oral health in institutionalised elderly people by 
educating caregivers: a randomised controlled trial. Community Dent Oral Epidemiol 2001 29: 289-297.

4. Nicol R, Sweeney M P, McHugh S, Bagg J. Effectiveness of health care worker training on the oral health of elderly residents of nursing homes. Community Dent Oral Epidemio/ 2005; 33: 115-124.

5. British Dental Association. Oral healthcare for older people: 2020 vision. BDA 2003.

6. Department of Health. Meeting the challenges of oral health for older people: a strategic review. Gerodontology 2005; 22: Supplement 1.

DOI: 10.1038/sj.bdj.2009.562

\section{CLARIFIED ELEVATORS}

Sir, we would like to thank Fitzgerald and Sawbridge for their correspondence $^{1}$ in relation to our article on the history of commonly used dental elevators, ${ }^{2}$ however, we would like to clarify a few points.

We did not set out to give the entire history of dental elevators, but merely started the introduction to the topic at a point in time and stage of development/evolution when these instruments became noticeably similar to the modern day equivalents, and when associated dates and names became definite. The main thrust of the article is on the history of the modern day elevators ie Warwick James, Cryers and Couplands that are in current use.

As stated at the end of our article, ${ }^{2}$ 'The list of elevators currently available to purchase is extensive (at least 33 different named instruments!). These could potentially be the focus of a future research project.' Therefore, any of these could have originated from any number of sources, such as instruments in Roman times or at the time of Celsus, but we focused on three named modern day types. We would welcome any information on the origin of any of the other named elevators.

Celsus may have described an operation which would (or could) require the use of an elevator; however, it is supposition to say that an elevator may have been required when no details of the instrument(s) available are described.

Firstly, from the text quoted, the description of the procedure fits more closely with the use of a curette type instrument ('scraped all round, that the gum may be loosened from it'). The concept that the gum may be scraped away from a tooth by an instrument that is not an elevator is described by Fauchard
(1678-1761), who advised separating the tooth from the gum with a very sharp lancet $^{3}$ and also by Benjamin Bell who described a scarificator to freely separate the gums from the stump (in 1786). ${ }^{4}$

Secondly, the next part of the procedure seems even closer to a description of an extraction with a forceps type device ("then it is to be shook; which must be continued till it move easily'). This is supported by the finding that forceps are the first described oral surgical instruments, with the oldest dental forceps in existence dating back to 50 $\mathrm{AD}^{5}$ and by the description of shaking a tooth with forceps before extraction with a Pelican in $1575 .^{6}$

Regarding the dental and surgical instruments from the Roman period, there is only very vague resemblance to modern day elevators, they could quite easily be curettes, retractors or probing/ exploratory instruments and we do not think it is possible to identify exactly what these instruments were used for, as Fitzgerald and Sawbridge say '..which may be elevators..', there is no actual detail provided on what these instruments were used for, or the techniques employed with them.

M. A. Bussell, Birmingham R. M. Graham, Liverpool

1. Fitzgerald $R$, Sawbridge D. Enjoyable elevators. BrDent J 2009; 206: 396.

2. Bussell M A, Graham R M. The history of commonly used dental elevators. Br Dent J 2008; 205: 505-508.

3. Atkinson H F. Some early dental extraction instruments including the pelican, bird or axe? Aust Dent J 2002; 47: 90-93.

4. Colyer F. Old instruments used for extracting teeth, 1st ed. Staples Printers Ltd.

5. Glenner R A. The dental office a pictorial history, 1st ed. 1984.

6. Dummer S. Instrument Darwinism. BDA News 2008; 21: 22.

DOI: 10.1038/sj.bdj.2009.563

\section{HYGIENE CONTROLS}

Sir, we have read with interest the Department of Health document HTM 0105 and recognise its vital importance as a contribution to minimising cross infection risks. However, the document appears to be mainly concerned with technical systems to assure cleaning and sterilisation of instruments. In dental practice it is equally important to have effective hygiene controls in the surgery itself. Sophisticated equipment for instrument sterilisation clearly has a part to play, but does not absolve us from responsibility for establishing and maintaining adequate systems for contamination control during treatment.

In almost any other hygiene-sensitive working environment, there are detailed operational standards supported by auditing and certification. Such standards include 'working practices' as well as technical requirements. The comparability of such arrangements with what might be appropriate to the dental surgery may be a matter of debate. What is important is that, as a profession serving a public who rely on dentists to exercise due care, dentists must be clear and confident that they are working to effective, reliable and recognised protocols.

There is some published evidence suggesting that typical working practices in the surgery do not achieve good control of potential routes of infection. If this is the case, the guidelines in HTM 0105 do not represent a completely satisfactory breadth of control.

People (patients, dentists and dental staff, not instruments) are the source of contamination; breaking the "chain of contamination' requires an understanding of the issues, coupled with appropriate behaviour and working practices. Surely a first step is to ensure the 'software' (hygiene practice) of cross infection control is in place before the insistence that the very demanding and prescriptive advice on the 'hardware' (cleaning and sterilising equipment) is implemented on the basis that all the hardware in the world can be undone in a moment by ineffective software.

Perhaps the time has come for a considered debate about the aims and methodology of dental cross infection control, particularly with regard to dental procedures and staffing requirements. There can be little debate on the efficacy of the processes required by the Department of Health guidelines. However, it is not good enough to point to the literature and observe the limited number of recorded examples of patient harm through cross-infection. This does not and must not be cited as a reason for inaction.

J. M. Ewart, W. A. D. Jack, A. A. Jack By email DOI: 10.1038/sj.bdj.2009.564 